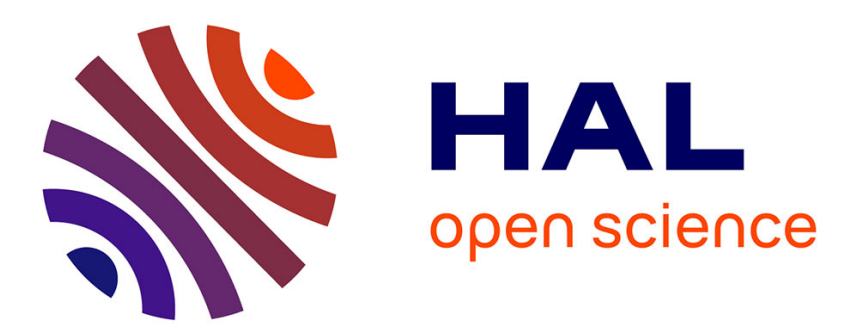

\title{
A product functional modelling approach based on the energy flow by using characteristics-properties modelling
}

Roozbeh Babaeizadeh Malmiry, Jean-Yves Dantan, Jérôme Pailhes, Jean-François Antoine

\section{- To cite this version:}

Roozbeh Babaeizadeh Malmiry, Jean-Yves Dantan, Jérôme Pailhes, Jean-François Antoine. A product functional modelling approach based on the energy flow by using characteristics-properties modelling. Journal of Engineering Design, 2016, 27 (12), pp.817-843. 10.1080/09544828.2016.1235261 . hal01394715

\section{HAL Id: hal-01394715 \\ https://hal.science/hal-01394715}

Submitted on 9 Nov 2016

HAL is a multi-disciplinary open access archive for the deposit and dissemination of scientific research documents, whether they are published or not. The documents may come from teaching and research institutions in France or abroad, or from public or private research centers.
L'archive ouverte pluridisciplinaire $\mathbf{H A L}$, est destinée au dépôt et à la diffusion de documents scientifiques de niveau recherche, publiés ou non, émanant des établissements d'enseignement et de recherche français ou étrangers, des laboratoires publics ou privés. 


\title{
A product functional modelling approach based on the energy flow by using characteristics-properties modelling
}

\author{
Roozbeh Babaeizadeh Malmiry ${ }^{a}$, Jean-Yves Dantan ${ }^{a}$, Jérôme Pailhès ${ }^{b}$ and \\ Jean-François Antoine ${ }^{a}$ \\ a LCFC, Arts et Métiers-ParisTech, HESAM, ENIM, Metz, France; b I2M-IMC-UMR 5295-Arts et Métiers, Talence, \\ France
}

\begin{abstract}
The main objective in designing a product is to satisfy the required needs. So, the designer aims to design the product's structure based on the required function of the product. Therefore, in the design process, the link between the functional requirement and the physical structure has to be assured. This paper proposes an approach to help the designer in transition from function to structure to assure this link. This approach uses energy flow modelling to model the system's behaviour in the framework of characteristics-properties modelling (CPM). It is composed of a multi-level modelling approach with two concurrent, interlinked modelling domains: functional and structural. By zigzagging between these two domains in each level of the decomposition, a quantitative model of the product is determined using CPM. The result shows the effective modifiable parameters (or required structure) of the product to satisfy the required function. So, it can be used to design a new product as well as analysing and optimising an existing product.
\end{abstract}

\section{ARTICLE HISTORY}

Received 4 February 2016

Revised 7 September 2016

Accepted 7 September 2016

\section{KEYWORDS}

Design theory and methodology; product modelling; energy flow model; functional modelling; oil pump

\section{Introduction}

The field of 'design theory and methodology' (DTM) includes a series of methods to help the designer in the process of product development. According to Pahl et al. (2007), there are four main phases in design:

(1) Planning and task clarification: to plan the design process and to collect information about the requirements and constraints.

(2) Conceptual design: In this phase, the principle solution based on the problem is determined. After establishing function structures and searching for suitable working principles, the solution is combined into a working structure. As a result of this phase, the 'concept' is specified by deciding between alternative principle solutions that are evaluated against the requirements collected in the first phase.

(3) Embodiment design: In this phase, the concept has to be concretised and detailed with technical and economic criteria as guidelines. The result is the module structure and 
layout of the solution. This phase continues to the point where subsequence detail design can lead directly to production documentation.

(4) Detail design: This phase is about the details of the design including forms, surfaces, dimensions, and tolerances of the individual parts. Moreover, the material specifications, cost estimations, manufacturability assessments, and production documentation is done in this phase. Some of this information is already determined in the embodiment design phase. So, there is not fixed boundary between this phase and the previous one.

For each phase, the designer needs to formalise the descriptions of the product, including functional descriptions, behavioural descriptions, and structural descriptions. To do so, a methodology is needed to structure these descriptions as well as certain rules to ensure the coherence of all descriptions. Such a methodology should be capable of giving feedback in each phase to the previous phase (Cross 2000).

In each phase, the potential solutions for fulfilling the needs are evaluated by comparing them with each other and against the problem or need (Blessing and Chakrabarti 2009). In the embodiment design phase, a model of behaviour is required which is based on the structure of the product. The structures are the potential solutions (concepts) as the result of the conceptual design phase. Therefore, the required model in the conceptual design phase should not only be able to abstract the problem and search for suitable working principles, but also be functional and structural. Besides, during the embodiment design phase, the designer needs mathematical models to use for predimensioning and dimensioning of the product. Furthermore, such mathematical models are useful for probabilistic sensitivity analysis and optimisation and will be a better foundation for the detail design phase. Thus, the focus of this paper is to propose a methodology or approach to help the designer in transition from required function to the physical structure and therefore to create a pathway for the designer from conceptual design phase to embodiment design phase.

Among the tools and techniques, function-behaviour-structure (FBS) (Gero 1990) is a model that can be used in both phases of conceptual and embodiment design for the decomposition of the system. FBS identifies the elements of the system as function, behaviour, or structure. By using a knowledge representation diagram, in a systematic approach, the designer starts from the function of the product and therefore the behaviour of the system to find the proper structure and so the design of the product (Gero and Kannengiesser 2004; Gero and Neill 1998). By using FBS, one is able to determine function and physical behaviour of the components and therefore decompose the system.

Because of the nature of relationships in FBS, one cannot achieve a quantitative model. So, another approach is needed with the advantages of FBS but also be able to use mathematical formulas as the relations between the parameters. This paper is looking for an approach that is more formalised than FBS. In FBS, there is no strict separation between physical parameters and behavioural parameters. The proposed approach has a more systematic approach for modelling products than FBS.

In light of this, characteristics-properties modelling (CPM) is used as a modelling framework. CPM is first proposed by Weber (2005a) and it uses an approach called propertydriven development (PDD) to gradually model the product. CPM/PDD, which is one of the DTMs, is 'an extended approach to modelling products and product development 
processes' (Weber 2005a, 159). CPM can be used as a framework in transition from embodiment design phase to detail design phase and it has the capability of integrating mathematical equations. It is based on the distinction between 'characteristics' $\left(C_{i}\right)$ and 'properties' $\left(P_{j}\right)$ of a product and the relations between them. For instance, the weight of a substance (a property) depends on the dimensions and material (characteristics). In a synthesis-analysis-evaluation cycle which is controlled by the properties, the model of the product is built (Tomiyama et al. 2009) while the designer is constantly looking for reducing the gap between as-is-properties $\left(P_{j}\right)$ and required properties $\left(\mathrm{RP}_{j}\right)$.

Since Weber's proposition, several articles, mostly by involving the creator, have been published. A number of them present the general concept of CPM (Conrad et al. 2008; Weber 2005a, 2008), while other articles are about different aspects of CPM (Köhler et al. 2008; Qureshi et al. 2011; Weber 2007). CPM is a suitable framework for the transition and it is easy to understand, though there are few weaknesses that led the authors to this study.

First, CPM/PDD is based on the distinction of the system's parameters as characteristics and properties and the model is created based on their relations. However, identifying these parameters with limited knowledge about a system is not easy. Second, creation of the structural model (in embodiment and detail design phases) according to the required function (in conceptual and embodiment design phases) is not assured. Third, as Weber indicated, the model has the capability of integrating other methods, but integration of common methods, along with examples of case studies has not yet been illustrated, except few articles (Conrad et al. 2007; Dantan et al. 2013; Erbe, Paetzold, and Weber 2011). Fourth, there is no systematic approach to create and analyse a system model by applying CPM on a real case study. The difficulty in the applicability of CPM/PDD and identifying the parameters of this method led us to propose an extended version of CPM. In this extended version, a complementary model is used, instead of PDD, to create the system model in CPM. Using PDD, the model becomes complicated for systems with so many relations and properties. The complementary model creates a link between function and structure of the product, and distinguishes the functional properties from other properties to be used in identifying the elements and relationships in CPM.

With this in mind, energy flow modelling (EFM) is proposed to model a system's behaviour in the framework of CPM. EFM studies a system based on the energy flow. One of the EFMs is the one proposed by Pailhès et al. (2011). This model, which is also called CTOC (due to the elements of converter, transmitter, operator, and control), is used for system behaviour modelling. It is utilised in the proposed approach to study the function of a system through sub-systems' decomposition, to obtain mathematical formulas describing physical phenomena. CTOC focuses on the minimum requirements that are needed in a system to satisfy the required function. It assures the transition from function to physical structure. In CTOC, the structure does not have to be known but rather the structure can be built based on the functional requirements by using the energy flow.

Thus, the proposed approach of this paper is to use CTOC in the framework of CPM in a top-down systematic approach. The approach is composed of a multi-level modelling approach with two concurrent, interlinked modelling domains: functional and structural. In each level of the decomposition, CTOC is used to identify the elements of CPM to create the system's model. Therefore, the system's structure is modelled based on the minimum requirement in order to satisfy the needs. The result will be a model of system including 
functional, behavioural, and structural descriptions of the product to be used in transition from conceptual to embodiment design phase. The created model can also be used to analyse the impact of system's elements on the output of the system.

In the following sections first two models of CPM (including initial and extended versions) and CTOC are presented. Then, a step-by-step approach is proposed including the interoperability of CTOC and CPM in addition to a set of rules. For better understanding and clarification of the proposition, a case study is presented in Section 5.

\section{CPM: a framework}

Over the years so many design theories and methodologies have been developed. Tomiyama et al. (2009), Le Masson, Dorst, and Subrahmanian (2013), and Blessing and Chakrabarti (2009) gathered some of these methods. Tomiyama (1997) categorised them in two axes of 'general vs. individual' and 'abstract vs. concrete'. The framework of the proposed approach is one of the 'concrete and general' methods in this category.

There are several criteria that define a method as more reliable and suitable to use. Despite having a general applicability and a systematic approach, the method should be practical and easy to understand. As aforementioned, the method should be used as a framework for design analysis. So, methods such as adaptable design (Gu, Hashemian, and Nee 2004) or design for X (DfX) (Huang 1996; Tichem 1997) which are for specific purposes, or the universal design theory (UDT) (Grabowski and Lossack 2000; Grabowski et al. 1998) which is to combine findings about product design from various scientific disciplines have not been used as the framework in the conceptual/embodiment design phase. Hence, methods such as axiomatic design (Suh 1990, 2001) or the Taguchi method (Taguchi 1987), thanks to the nature of their approaches, could be used for this purpose.

Among DTMs in this context, CPM/PDD has a general and systematic approach and it is suitable for the embodiment design phase. It gives a framework into which other DTM approaches such as axiomatic design as well as Pahl et al. (2007) and Haubka and Eder (1987) can fit. It also gives a background to integrate other methods such as DfX. In addition, it can explain some open design theories and it delivers a theoretical base for the development and use of methods and tools in the development process, including CAX (Conrad et al. 2007; Tomiyama et al. 2009). Furthermore, it works with mathematical relations (among other types of models) and finally it is suitable to model systems with design complexities.

\subsection{Introduction of the method CPM/PDD}

About 10 years ago Weber developed CPM and PDD for product/system modelling and to explain the process of developing and designing the products, respectively. As previously stated, CPM is based on the distinction between 'characteristics' and 'properties' of a product. The characteristics are called 'internal properties' in Hubka and Eder (1996) and 'design parameters' (DP) in Suh (2001). The properties are similar to 'external properties' of Hubka and Eder and 'functional requirement' (FR) in axiomatic design theory of Suh (Weber, Werner, and Deubel 2003; Weber 2005a, 2009). 


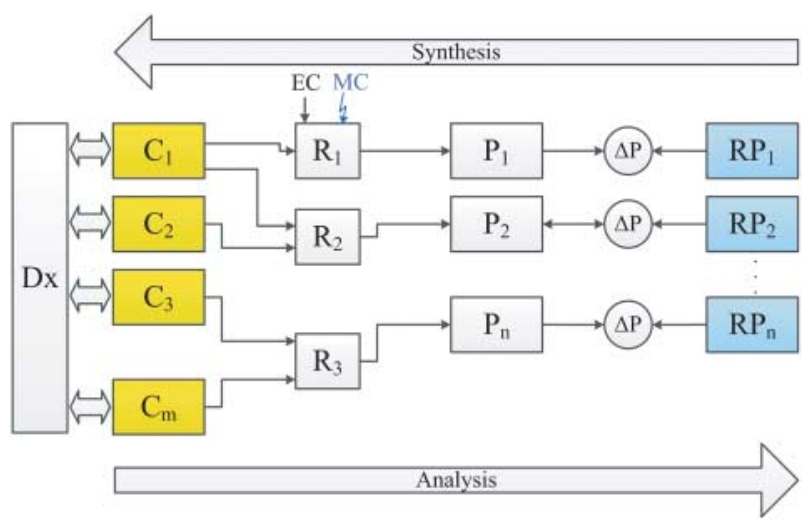

Figure 1. CPM/PDD representation extracted from Köhler et al. (2008) and Weber (2007).

The definition of the elements of CPM according to Weber is as followed:

Characteristics $\left(C_{i}\right)$ are the parameters that can be directly influenced or determined by the designer. For instance, shape, structure, dimension, bill of material (BOM), material, and surface of the product.

Properties $\left(P_{j}\right)$ stand for the product behaviour which means the parameters that the designer cannot change directly but they can be changed indirectly by means of the characteristics. For instance, function, weight, aesthetic properties, safety and reliability, cost, and manufacturability.

Relations $\left(R_{\mathrm{m}}\right)$ represent the interrelation between characteristics and properties.

Required properties $\left(\mathrm{RP}_{j}\right)$ are the parameters that the designer has to achieve, based on desires of the customer/user, restrictions/strategies of the own company, societal issues (e.g. legislations), etc.

Figure 1 illustrates a general model of CPM/PDD. In PDD, Weber proposes four major steps to build the model first, and then to develop the product:

(1) The process starts with a list of requirements $\left(\mathrm{RP}_{j}\right)$. The designer establishes the first major characteristics $\left(C_{i}\right)$ based on some of the required properties. In many practical cases in this step, a partial solution is already known from previous designs.

(2) In the second step, the properties of the current solution $\left(P_{j}\right)$, based on the established characteristics, are analysed. In this step, all relevant properties are considered, not only those that went into stablishing the characteristics in step 1.

(3) In the third step, the result of the analysis in step 2 is used to determine the deviation of the individual properties against the required properties. This deviation $\left(\Delta P_{j}\right)$ determines the shortcomings of the current design.

(4) The fourth step is the overall evaluation. In this step, the main problems are extracted and it is decided on how to proceed. In many cases (especially in early stages of the design), the property(/ies) with the biggest deviation between as-is and required states are chosen and appropriate methods are implied in order to modify the characteristics 
(i.e. plan the next synthesis step). This cycle continues until the vector of $\Delta P_{j}$ is small enough to be acceptable.

Other than the characteristics and properties, there are other parameters that influenced on the system. These parameters are called external conditions $\left(\mathrm{EC}_{k}\right)$. According to Weber $(2007,90)$ : 'The determination/prediction of every product property via an appropriate model, method and tool must be performed with respect to these parameters'.

For a more straight-forward definition of EC, we defined it as:

External conditions $\left(\mathrm{EC}_{k}\right)$ are the parameters that the designer cannot change directly and uniquely, and also they cannot be changed indirectly by modification of the characteristics. In other words, external conditions are defined by the external environment in which the designer does not have control over.

To be noted, in some cases, the designer decides to consider new aspects of a system in the design. In this case, $\mathrm{EC}_{k}$ becomes a property. For instance, manufacturability requirement is an $\mathrm{EC}_{k}$ in the initial model but then, the designer decides to model the manufacturing system of the product as well (design for $\mathrm{X}$ ). In this case, manufacturing requirement is not an external condition but it is a property with its related characteristics.

Another element that needs clarification is 'modelling condition':

Modelling conditions $\left(\mathrm{MC}_{n}\right)$ are 'the set of assumptions, hypothesis, boundary conditions or simplifications used while developing the model that have to be taken into account for defining the relations between the characteristics and the properties'. (Dantan et al. 2013, 148)

Bear in mind that in design, what is called 'parameters' in general, can be any of the CPM elements (characteristics, properties, or external conditions).

\subsection{An extended version of CPM}

In Section 2.1, the initial CPM/PDD is presented. In PDD, the model of product is created by a synthesis-analysis cycle. The representation of the model, as illustrated in Figure 1, is not applicable easily to design products with complicated relationships. In this paper, inspired from the initial model, we propose an extended version of CPM to model the product. In this approach, the systematic top-down approach in axiomatic design (Suh 2001) is used. This approach is illustrated in Figure 2.

As Figure 2 shows, the decomposition of a system is done in two domains in parallel: functional and physical domains. The study starts from the highest level of conceptual design where there is enough information about the required function of the system. Then, from an FR in the functional domain, we conceptualise the design and determine the corresponding DP in the physical domain. Then, we go back to functional domain and decompose $F R$ into two $F R_{1}$ and $F R_{2}$ that collectively satisfies FR. This zigzag approach continues until the FR can be satisfied without further decomposition (Suh 2001). As mentioned before, FR is the same as $P_{j}$ and DP is the same as $C_{i}$. However, the definition of function in axiomatic design and CPM is not the same. In this paper, function is only those properties that transform given inputs into required outputs. 


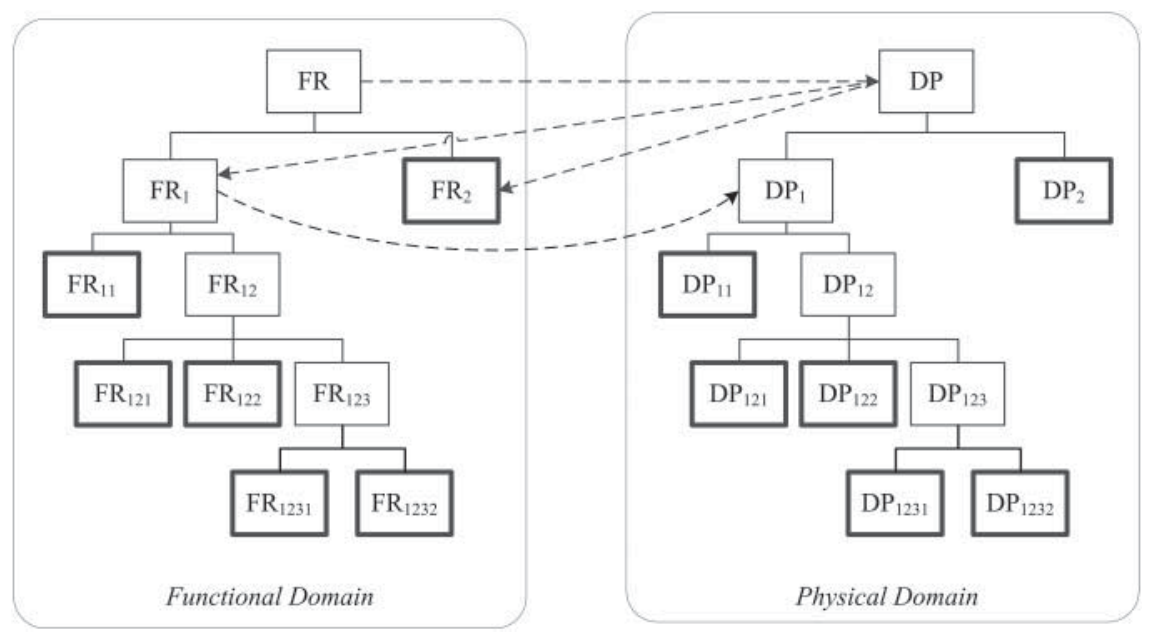

Figure 2. Zigzagging approach in axiomatic design (Suh 2001).
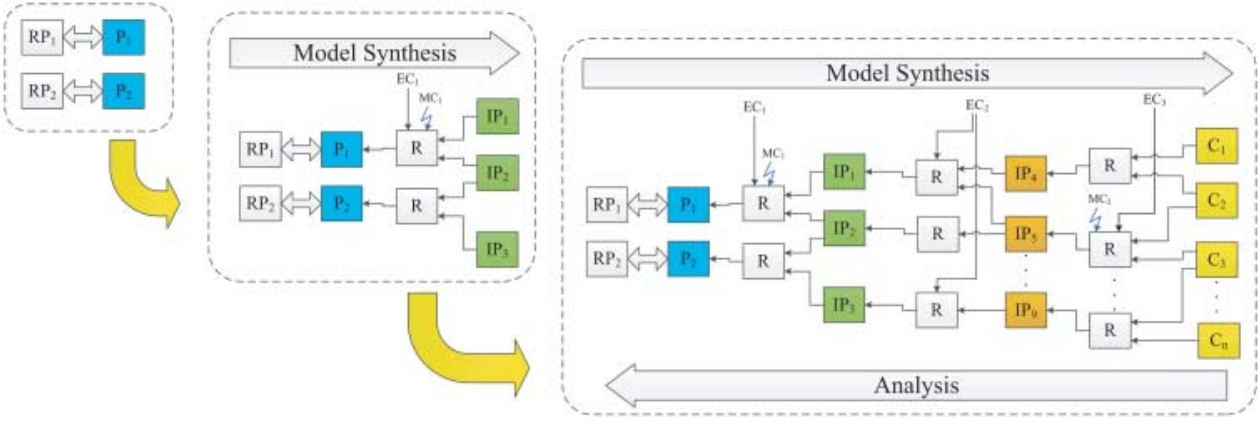

Figure 3. An extended version of CPM.

Unlike PDD, our proposed approach uses the hierarchical approach similar to axiomatic design to identify the elements of CPM. So, the designer starts with required properties $\left(\mathrm{RP}_{j}\right)$ similar to FR in Figure 2. Based on that, the main properties $\left(P_{j}\right)$ are identified (similar to DP in Figure 2). By zigzagging between functional and structural domains, the system is decomposed and important parameters are identified. When there is no further decomposition, the identified elements are controllable by the designer. So, based on the definition they are considered as $C_{i}$. All the identified parameters after the first level and before the final level of decomposition are called 'intermediary properties' $\left(\mathrm{IP}_{j}\right)$. So

\footnotetext{
Intermediary properties are those parameters that cannot be categorised with characteristics or external conditions based on the definition. They are properties but different from as-isproperties. They are used to decompose the as-is-properties and to find/represent the related characteristics of a property in a complex system while decomposing the system. So, they are the intermediary parameters between the as-is-properties and characteristics.
}

During the zigzag approach between two domains, by using the identified elements in each level of decomposition, CPM is built step by step. A general construction approach of product model using the extended version of CPM is shown in Figure 3. 
In a complex system, identifying the characteristics at first is not always possible. This hierarchical decomposition of the required function helps the designer to decompose the design problem into smaller sub-problems.

Thus, actually the use of Weber's methodology as called CPM/PDD in our approach is limited to the following concepts: the concept of identifying the parameters as characteristics and properties; the synthesis approach to start from required properties, properties and arrive to characteristics; and the analysis approach to analyse the impact of effective parameters on the system's output.

In the proposed approach using the extended CPM, a complementary tool is needed to identify the CPM elements, to assure the link between functional requirements and physical structure and to extract the physical laws in order to determine the quantitative model.

There are various tools and techniques in product design (Lutters et al. 2014) that can be integrated in CPM. Quality function deployment (QFD) is one of these tools to involve the competitors and customer satisfaction in the process of design (Mizuno and Akao 1993). Failure mode and effect analysis and reliability engineering plan are tools for risk analysis and reliability analysis of the product during the functioning of the product (McDermott, Mikulak, and Beauregard 1996). In addition, the design structure matrix is another tool to manage complexity by concentration on information flow and interdependencies within and between different domains (Browning 2001; Pektas and Pultar 2006). These tools, considering their specific capabilities in different aspects, can be integrated in CPM but cannot be used for functional-structural modelling. Internal block diagram (IBD) and parametric diagram are two of the models in SysML (Friedenthal, Moore, and Steiner 2012) to model the structure of a system. IBD is based on an existing solution. We need a tool to integrate in the approach in order to help the designer in decision-making to determine the possible solutions. The parametric model considers the element of a system as parameters without distinction between $C_{i}$ and $P_{j}$ or between functional parameters and physical parameters. Moreover, in any of these models the notion of modelling condition $\left(M C_{n}\right)$ does not exist.

We propose energy flow to model the behaviour and identify the CPM elements in addition to their relations. There are energy models such as bond graph (Borutzky 2010; Paynter 1961) and four-pole/multi-pole models (Oppelt 1972; Weber 2005b) that can be integrated to CPM. Bond graph is used to describe a system based on an existing structure. Without knowing the system structure, modelling in bond graph is not effective. Four-pole/multipole models can model the structure without complete knowledge of the designer and extract the physical laws. However, it focuses on the structure modelling and not the link between functional requirements and physical structure.

Thus, the energy flow model of CTOC (Pailhès et al. 2011) is proposed to interoperate with CPM in order to satisfy the above-mentioned objective. CTOC focuses on the minimum structural requirement of a system to satisfy the needs. So, instead of considering all the flows (like in bond graph, IBD or four-pole/multi-pole models), it focuses on the flows that are necessary to achieve the required function. Since the analysis is based on the functional requirement, in modelling by CTOC, the structure is not necessarily known but rather the structure can be built based on the functional requirements. So, unlike other aforementioned models, it can be used before knowing the description of a system. In the following sections, it is shown how CTOC in our approach can help the designer to assure the transition from function to structure. 


\section{CTOC: an energy flow model}

The energy model proposed by Pailhès (Pailhès 2013; Pailhès et al. 2011; Pailhès, Sallaou, and Nadeau 2007) is based on the design theory of TRIZ (Altshuller 1984, 1999). TRIZ or 'theory of invention problem solving' contains a set of tools and methodologies for generating inventive solutions for design problems. One of the eight 'laws' of technology evolution in TRIZ is the 'law of completeness of system parts' (Altshuller 2008; Savransky 2000). This law, which decomposes the system into specific entities, focuses on the minimum requirements to describe a system. СTOC analyses the functioning of the product according to the flow of energy. Using this law, component of a system can be defined based on transmission and transformation of energy. Energy flow analysis of CTOC creates a link between functioning of a system and structure of its entities.

СTOC creates a systematic functional decomposition of a system in transition from conceptual design phase to embodiment design phase. Moreover, in a product design process with complexities, this model can decompose the design problem into smaller thus more manageable sub-problems (Pailhès, Sallaou, and Nadeau 2007).

In general, the function of a system can be defined as the transformation of one basic entity into another within an artefact. These entities which could be material, energy or signal, can express the function in different levels to decompose the system (Henderson and Taylor 1993). Among these entities, Pailhès, Sallaou, and Nadeau (2007) believe that it is possible to express the principle flow associated with conducting the main function(s) in terms of energy flow(s).

This model has the same basis as the three fundamental premises (Sushil 2002) in 'physical system theory' (PST) (Koening, Tokad, and Kesavan 1967). Similar to CTOC, PST is initially developed to model and analyse discrete physical systems and therefore to represent the physical relationships in a system (Sushil, Singh, and Jain 1988; Sushil 1991). However, unlike PST, CTOC is not based on the representation of all flows in a system but only the functional flows. Functional flows are those that are necessary to satisfy the required function.

According to the energy flow, a system could consist of:

Convertor (C): It converts the input energy into another type of energy to be used by other components of the system.

Transmitter (T): It transmits the received energy without changing the type of energy. Operator (O): It fulfils the required action depends on area of operation. According to design situation, the operator can be a transmitter or a convertor.

Control (C): It insures that different components perform correctly.

Reference: It insures maintaining the position of different entities (convertor and transmitter) to support smooth passage of energy flow.

In general, convertor, transmitter, operator, control, and reference are denoted as СTOC 'entities' in this paper. Each component is defined based on its functioning regarding the input/output type of energy. The function of the interaction components (shown as a circle on each arrow) is to connect the components together and to allow the energy to pass smoothly.

Although, the main functions in CTOC entities are conversion and transmission, the flow might be provided or stored too. In case of providing or storing function, the conversion of 
Table 1. Classes of function in CTOC.

\begin{tabular}{lll}
\hline Function & Input energy & Output energy \\
\hline Transmit & Energy type 1 & Energy type 1 \\
Convert & Energy type 1 & Energy type 2 \\
Convert/provide & No input & Energy \\
Convert/store & Energy & No output \\
\hline
\end{tabular}

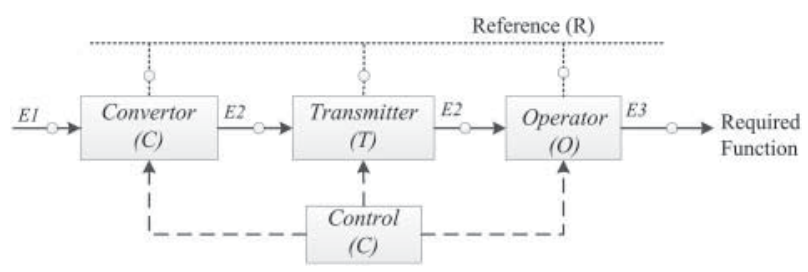

Figure 4. General structural model of a system according to CTOC.

energy is the conversion of external energy into potential internal energy and vice versa. For example, while storing water in a water tower, the hydraulic energy is being converted into potential energy of water. Table 1 shows which class of function to choose based on the input and output energy type.

While CTOC focuses on the necessary flows to satisfy the function, it also considers the induced physical phenomena that are not desired but existed. For example, when the functional flow in a system is thermal flow, two phenomena of deformation and dilatation are also taken into account. These phenomena and the instigated inevitable losses have to be considered in the design process. Managing these interactions is important in structural point of view since it not only allows creative designs, but can also generate a logical hierarchy of solutions. A general structural model of a system based on CTOC is shown in Figure 4.

This model is also applicable on products without functional flows as demonstrated on a chair as a case study in Pailhès et al. (2011). However, it is not recommended to use CTOC vision for such systems. This approach is most effective when the energy flow has an important role in the functioning of the system.

As mentioned before, the objective of CTOC is to create a coherent and structured passage from function to architectural solutions based on the behaviour of the system. After decomposition of the system by CTOC, the designer will have a better knowledge on the system and sub-systems based on the function of that component. Through this flow, the related parameters will be identified and the equation among them is determined. So, the importance of each component based on its functioning or in other words, its impact on the system will be recognised.

\section{The proposed model: energy flow in CPM}

The proposed approach of this paper which is to use CTOC in the framework of CPM in a top-down systematic approach along with a set of rules to apply is presented in this section. It has a systematic top-down approach similar to axiomatic design (Suh 2001) as presented. 


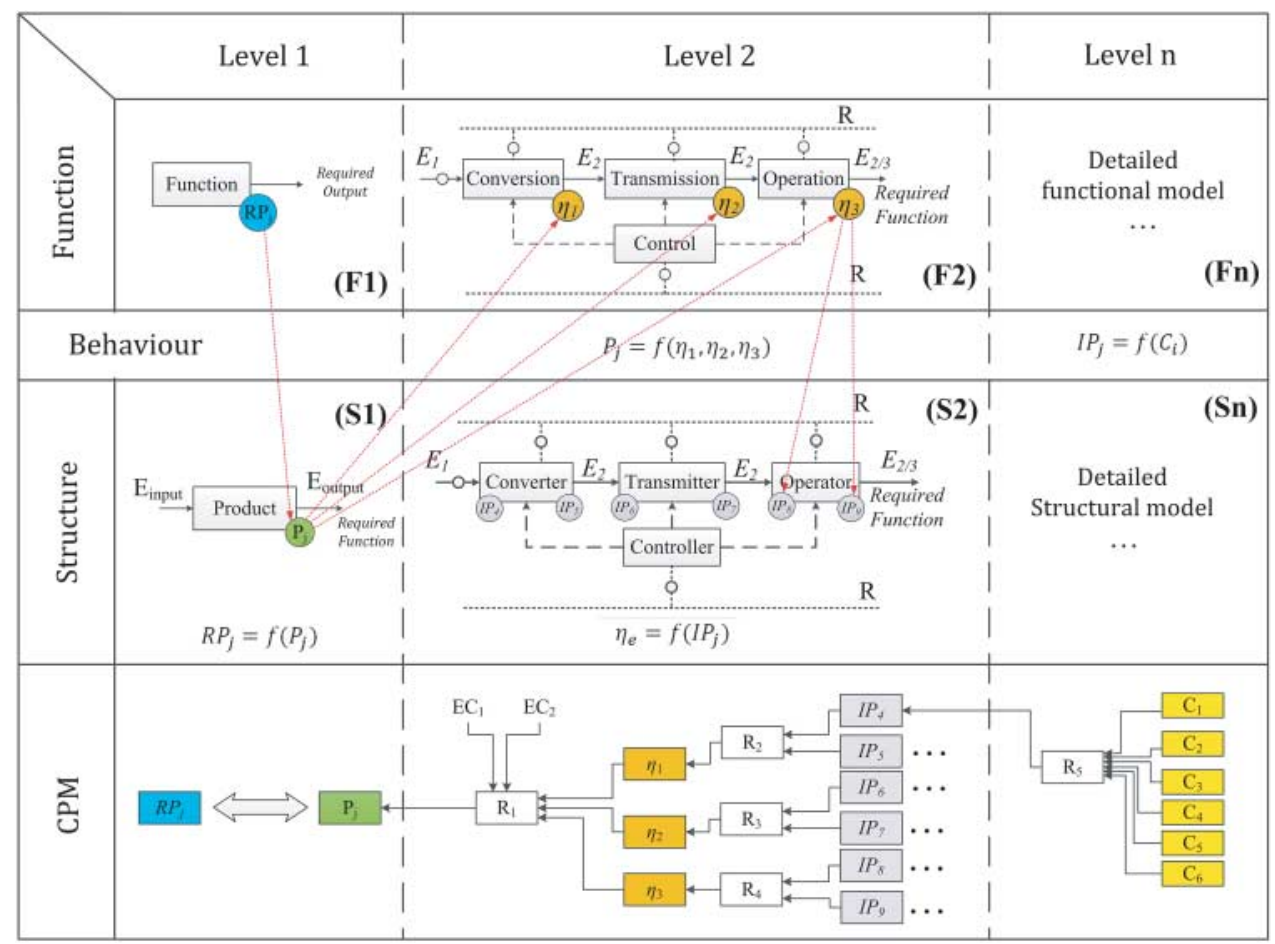

Figure 5. A general representation of the approach including three levels of decomposition.

In each level of decomposition, the approach includes two domains of functional and structural. In each level, the structural model is established based on the functional model of that level in addition to the required decisions that are made by the designer.

The approach begins with analysing the customer needs. Customer need, which has normally a qualitative value, should be translated into a quantitative value. This value in CPM terminology is considered as required property $\left(\mathrm{RP}_{j}\right)$. The next step is to define the function of the required system based on $\mathrm{RP}_{j}$. In many cases, the function can be defined as its consumption of resources or implementation of energy flow.

So, the function in this level is defined based on the energy flow to satisfy the required need. As an energy flow approach, the input and output of the system as types of energy should be identified. This identification is based on the definition of system's function in terms of energy. In other words, the function is also defined as transition or transformation of energy. So, the input and output are defined accordingly. A model of system in this level is shown in the function section of Figure 5 in level 1.

The structural model based on the functional model is created. If a product exists already with the same function as required, it can be chosen. In this case, the approach will have an optimising objective. If there is not such product, it can be defined. In this case, the approach is to design a new product. In the structural domain, the determined parameter is the main property of the system $\left(P_{j}\right)$. This parameter is chosen based on the $\mathrm{RP}_{j}$. In each level of decomposition, after identifying the important parameters, the system model is constructed based on CPM. So, $\mathrm{RP}_{j}$ and $P_{j}$ create the first part of CPM as shown in Figure 5-level 1. 
The following level of the approach uses the CTOC model to decompose and study the system based on the energy flow. In functional domain, the system's function is divided into sub-systems based on conversion (C), transmission (T), operation (O), and control (C) of energy. This model is shown in the 'function' section of Figure 5-level 2. In this level, one of the important groups of parameters is the efficiency of each sub-system.

Based on this model, the structural model is created. This model is shown in the 'structure' section of Figure 5-level 2. According to the function of each sub-system, a physical entity or a group of entities can be chosen to satisfy the required function of the sub-system. If such an entity does not exist, it is defined. If further decomposition is needed, using CTOC, sub-systems are analysed in more detail. The important parameters in this level are intermediary properties $\left(\mathrm{IP}_{j}\right)$ in CPM.

As the previous level, the system model in CPM is created using the determined parameters in functional and structural analyses. As every step, the relations should be found. A general representation of the relations from the structural model of level 1 and the functional model of level 2 is as follows:

$$
P_{j}=f\left(\eta_{i}\right)
$$

Here, efficiency is considered as the important parameter. This completely depends on the objective of the designer. Efficiency is only one of the possible $I P_{j}$. The second equation (relations) is between the determined parameters in functional domain of level 2 and structural domain of this level. A general formula is as follows:

$$
\eta_{i}=f\left(\mathrm{IP}_{j}\right) .
$$

Assigning/defining components in CTOC is started from the operator $(\mathrm{O})$ as the main entity. Then, based on the received types of energy, if transmitter ( $T$ ) or/and converter (C) is needed, they will be added. Despite these entities, if an entity is responsible for controlling the functioning of other components is named control (C). This approach in CTOC is applicable in both functional and structural domains.

As indicated, in the law of TRIZ, the designer should focus on the minimum requirements to describe the system. So, in modelling the system based on CTOC, dividing the system into the entities does not necessarily mean having all the entities of $C, T, O$, and $C$. The element of operator is obligatory since it contains the main function of the product. So without this entity the product would not exist. The entities of converter and transmitter are not obligatory to have. In other words, a system with only the entity of operator can be a complete system. In fact, the designer should try to achieve an ideal system with a minimum of necessary entities. With this approach, the complexity of the system will be reduced as well.

The element of control on the other side, though it is not obligatory, is desired. As aforementioned, this entity is responsible to assure the functioning of other components. So, although a system without the element of control can be a complete system, with this entity the result will be a more robust product.

As mentioned before, if any physical entity in the previous level needs to be decomposed further, it is done in the same way by CTOC. The final level is a detail (still in early stage of design) structural level. With the obtained knowledge about the minimum required entities from the energy flow model, the designer has a base for designing the product. 
For the structural model in this level, 'block diagram' which is one of the diagrams in system modelling language (SysML) (Friedenthal, Moore, and Steiner 2012) can be used. Although all kinds of relations (such as physical and signal ) can be used in block diagrams, the focus is on energy flow that is studied on the previous level. Moreover, other links such as with References have to be maintained as well.

As before, the important parameters, based on the objective, are identified. Using these parameters in the framework of CPM, a model of the system is created. A complete model means identifying all the effective parameters, depending on the objective, and their relations. A general representation of this model is illustrated in the CPM part of Figure 5 .

To be noted, if the identified parameters are a mixture of $C_{i}$ and $I \mathrm{P}_{j}$, they should be placed in two different columns in CPM. The reason is that, at the end of the model synthesis phase, all the characteristics should be placed in a single column which is the rightmost column. In this way, the model will be more comprehensive and the analysis will be smoother. In the analysis phase and later for improving the product, the designer will only modify the elements of this column to observe/modify the main property. A complete model of the product using the presented approach identifies the relationship between the main properties (Which are related to $\mathrm{RP}_{j}$ ) and other parameters. So

$$
P_{j}=f\left(C_{i}, \mathrm{IP}_{j}, \mathrm{EC}_{k}\right)
$$

Thus, by Equation (3), the designer can change the main properties $\left(P_{j}\right)$ by modifying characteristics $\left(C_{i}\right)$. Modification of $C_{i}$ will result in the changes of $I P_{j}$. Changes in each level will cause changes in the higher level. This process will be continued until the main $P_{j}$ is reached. The modifications are according to the comparison of $P_{j}$ with $\mathrm{RP}_{j}$. After analysing the effect of characteristics on main properties, the designer will have ideas about the improvement of the product. The direction of this improvement is to minimise the deviation between $P_{j}$ and $\mathrm{RP}_{j}\left(\Delta P_{j} \rightarrow 0\right)$.

To sum up, in this approach, there is a set of rules to follow:

- Rule \#1: The modelling is done in a systematic top-down approach.

- Rule \#2: The first model is the functional model based on the required output.

- Rule \#3: The structural model in each step is based on the functional model of that level and based on the designer's decisions.

- Rule \#4: The model of system is constructed step by step using the determined parameters and relations in each level of decomposition.

- Rule \#5: The number of decomposition levels is related to the objective of the designer and complicatedness of the system.

In CPM:

- Rule \#6: The identified elements $\left(C_{i}, P_{j}, \mathrm{EC}_{k}, \mathrm{IP}_{j}, \mathrm{MC}_{n}\right)$ of the system in CPM shall be based on the given definition.

- Rule \#7: Any parameters with impact on the system that are from the external environment are considered as $\mathrm{EC}_{k}$.

- Rule \#8: All the assumptions, hypotheses and simplifications while modelling the system, should be documented and shown in CPM as $M C_{n}$. 
- Rule \#9: $\mathrm{MC}_{n}$ shall be an acceptable condition according to the modelling objective and client expectations.

- Rule \#10: The first group of properties that is related to the objective includes main properties $\left(P_{j}\right)$, while other properties that are used for decomposition and better representation of the model are internal properties $\left(I P_{j}\right)$.

- Rule \#11: Depending on the objective, the model is complete when all required characteristics $\left(C_{i}\right)$ are identified.

In CTOC:

- Rule \#12: CTOC is based on the functional flows only and not all the system's flow. This is to model the minimum physical requirements of the system to satisfy the required function.

- Rule \#13: For each function of the product, there shall be at least one model of CTOC.

- Rule \#14: The coherence between the CTOC models shall be kept.

- Rule \#15: 'Operator' is the only obligatory entity in CTOC. Though, having the entity of 'Control' is strongly advised since it is to insure the functioning of other entities.

- Rule \#16: The energy flow in different levels of CTOC shall be in coherence with each other.

- Rule \#17: The important parameters and the relations $\left(R_{i j}\right)$ are based on the physical phenomena.

- Rule \#18: The identified relation in each model shall be a clear quantitative formula.

- Rule \#19: 'References' are not included in the main energy flow of the system but rather they are the contact of the system with external environment. In the decomposed levels, it shall be presented to illustrate the contact of the components of the system.

- Rule \#20: If all decisions are made and the structural model is known, then a full representation (by IBD or bond graph) shall be presented as the final model in the approach.

\section{Case study}

The objective in this case study is to deliver the oil with specific flow to the engine parts for lubrication. As one of the possible solutions for satisfying this function, a gear pump is used to analyse. The drive of this pump is taken from the internal combustion engine's rotating shafts. Since the solution exists, structural modelling would be easier since the structure of the solution is used. However, this case study is explained as if the product does not exist to show how the current structure is achieved.

The case study is an external gear oil pump used in the automotive industry. This pump pulls the oil from the tank and delivers it to the engine. This pump uses two gears which rotate inversely to deliver the oil. External gear pumps have close tolerances and shaft support on both sides of the gears. This allows them to run to pressures beyond 3000 PSI/200 bar, making them well suited for use in hydraulics. Usually in car engines it has the pressure of up to 20 bar. Additionally, due to the low cost of these types of oil pumps compared to similar models, it is used as the solution to satisfy the required function. A simple schema of an external gear pump mechanism is demonstrated in Figure 6. 

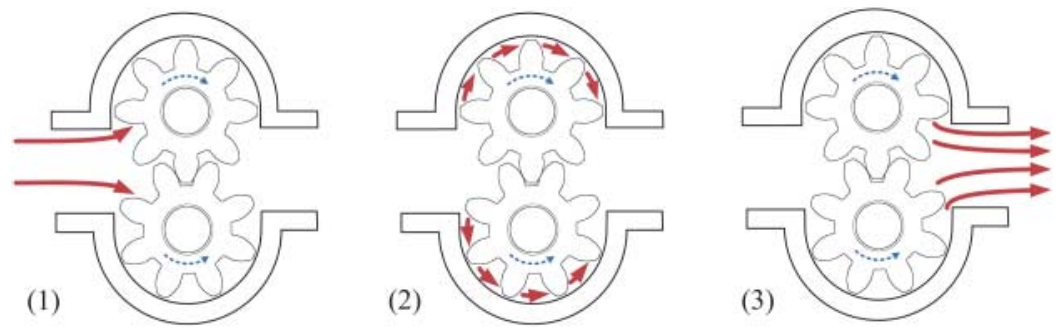

Figure 6. External gear pump mechanism.

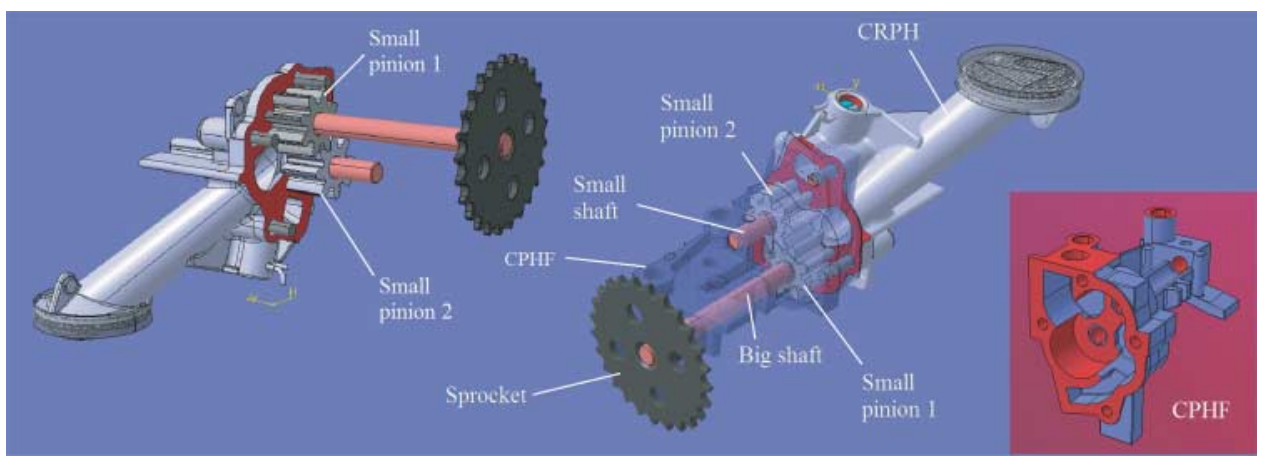

Figure 7. 3D model of an oil pump.

A 3D model of this pump is illustrated in Figure 7. The pump casing consists of two main parts of CRPH and CPHF. Inside the CPHF, there are two small pinions, a big shaft to transmit the energy from the sprocket and finally there are fixation screws to assemble two parts of the casing after the pinions have been inserted.

\subsection{Level 1: system analysis}

As mentioned, the study begins with identifying/defining the main function of the system to satisfy the required output. The main function is to 'deliver oil' and the required output is 'required flow' (RQ). So, the first model of the system as a black box will be as Figure 8(a). This model illustrates the objective of the modelling.

In an energy flow approach, the input, the output, and the function need to be defined in energy point of view. Regarding the required output of the system (oil flow), hydraulic energy is the output. The input depends on the chosen/considered solution. In this case, the input energy can be received from the engine by a chain. So, the input is mechanical energy. Therefore, the function of the system can be defined as the conversion of mechanical energy into hydraulic energy.

The structural model in each level of decomposition is created based on the functional model of that level and according to the designer's decisions. So, based on the model in Figure 8(a), the structural model is created as Figure $8(\mathrm{~b})$. In this model, the product is used for satisfying the required output. The required output is imposed by the manufacturer to have a flow of at least $5.46 \times 10^{-4} \mathrm{~m}^{3} / \mathrm{s}$ in minimum RPM for a car in the idle state in order to have enough flow for the lubrication of parts. According to this required output, $\mathrm{RP}_{j}$ is 


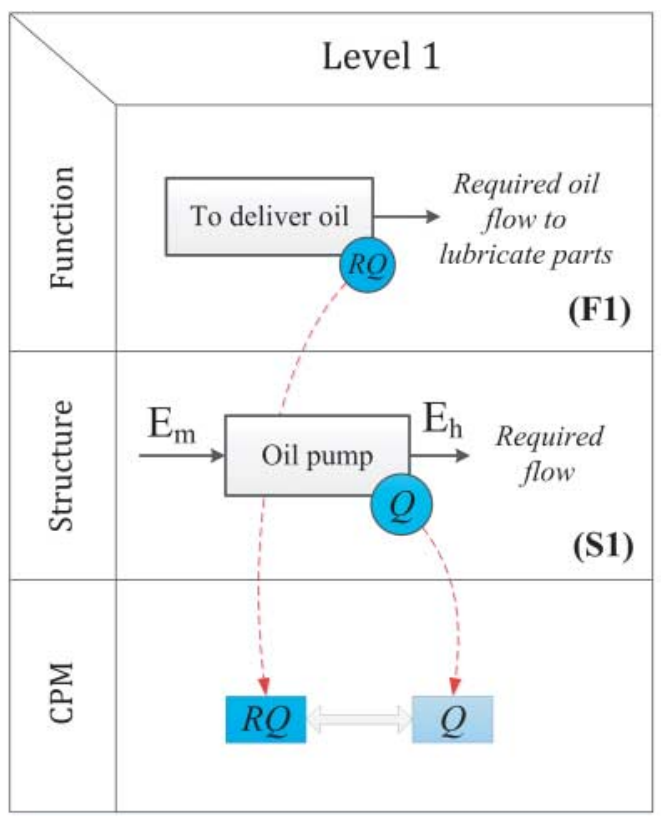

(a)

(b)

(c)

Figure 8. First level of modelling approach for an oil pump: (a) functional model; (b) structural model and (c) product model.

the required flow $(\mathrm{RQ})$ and based on that the as-is-property is defined as $Q$ (oil flow). So, the first level of the approach is illustrated as Figure 8.

\subsection{Level 2: system decomposition}

The second level is the decomposition of the system into sub-systems. At any level, first the functional study is done and then it is the structural study accordingly. The system function is divided into sub-system based on the entities of CTOC. The main sub-function is 'to generate hydraulic energy' so it is the entity of operator. The input for this sub-system is mechanical energy. However, a transmitter is needed to transmit the received energy from the engine into the zone of operation. In addition, control is needed to assure the pressure of outlet oil flow. In this system, a converter is not required since the received type of energy is the desired type (rotational mechanical energy). This functional model is illustrated in Figure 9(a).

One of the important parameters that can be used in this level of functional model is the efficiency of each sub-system. Since the transmitter transfers mechanical energy and the operator creates hydraulic energy. The hydro-mechanical efficiency $\left(\eta_{\mathrm{hm}}\right)$ and the volumetric efficiency $\left(\eta_{\mathrm{v}}\right)$ are proper indexes to compare the outlet flow with the inlet flow of the oil and therefore to be used as $\mathrm{IP}_{j}$. These parameters $\left(\eta_{\mathrm{v}}, \eta_{\mathrm{hm}}\right)$ are placed in the model as shown in Figure 9(b).

In each level of decomposition, the determined parameters create the elements of CPM step by step. Additionally, the relation $\left(R_{\mathrm{m}}\right)$ among the elements should be identified.

In order to obtain the first equation, the physical phenomena in the oil pump and its environment has to be studied. The input is the power that is received from the engine. 
(a)

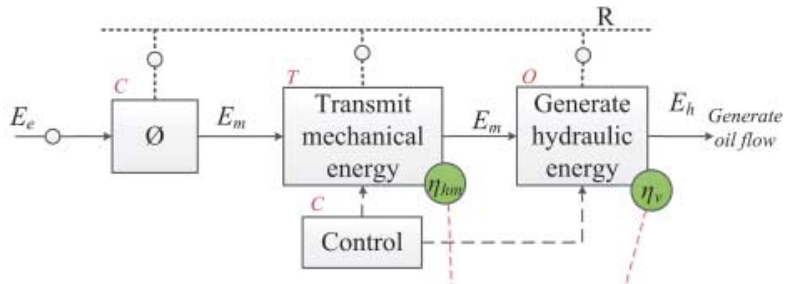

(b)

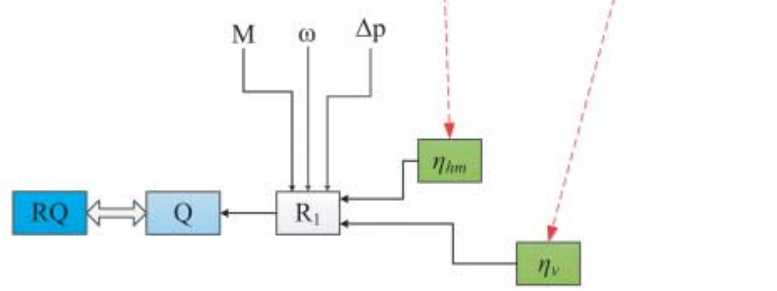

Figure 9. Second level of oil pump model: (a) functional model and (b) CPM.

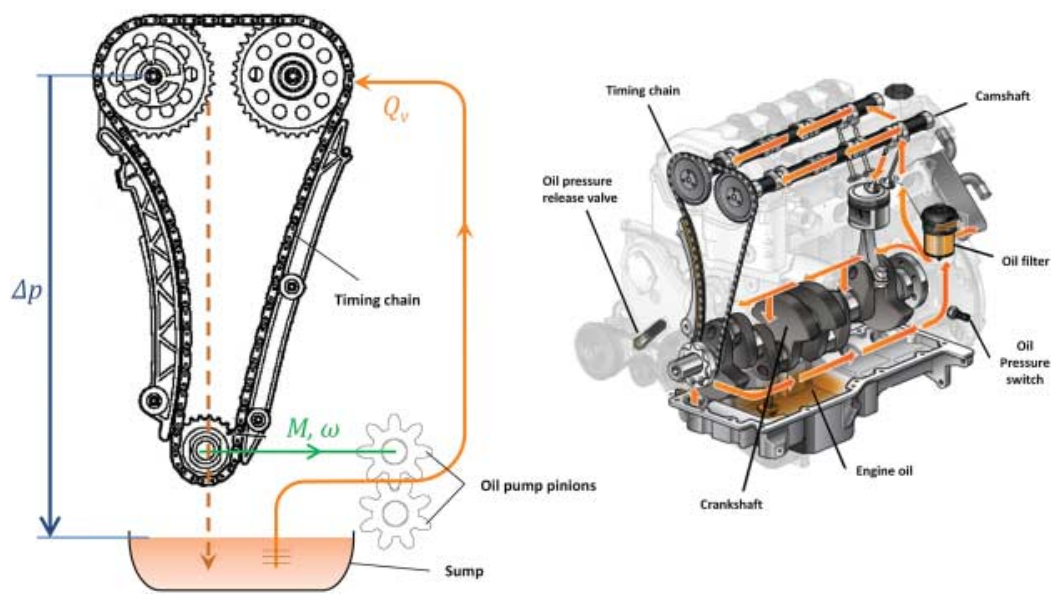

Figure 10. A simple schema of the energy circuit to illustrate why $M, \omega$, and $\Delta p$ are $\mathrm{EC}_{k}$.

So, it includes two parameters of $M$ (torque) and $\omega$ (angular rotational velocity). These two parameters are related to the engine behaviour. Therefore, the value of these parameters depends on the condition of the car which is controlled by the driver. The designer cannot control these parameters while designing the pump. So, $M$ and $\omega$ are two of the $\mathrm{EC}_{k}$.

In addition, the pressure rise $(\Delta p)$ is a function of $Q$ and it is imposed by the hydraulic load. As Figure 10 shows part of the energy circuit in the car engine, the mechanical energy $(M$ and $\omega$ ) is received by a chain and the pump creates flow with pressure for lubrication in order to reduce friction and heat in the engine. When the oil circulates in the engine parts, the pressure descends and then again it is increased by the pump when the flow is generated. So, $\Delta p$ is not related to the structure of the pump but to the engine characteristics. $\Delta p$ cannot be controlled by the designer in the pump design and it is also considered as an $\mathrm{EC}_{k}$. 


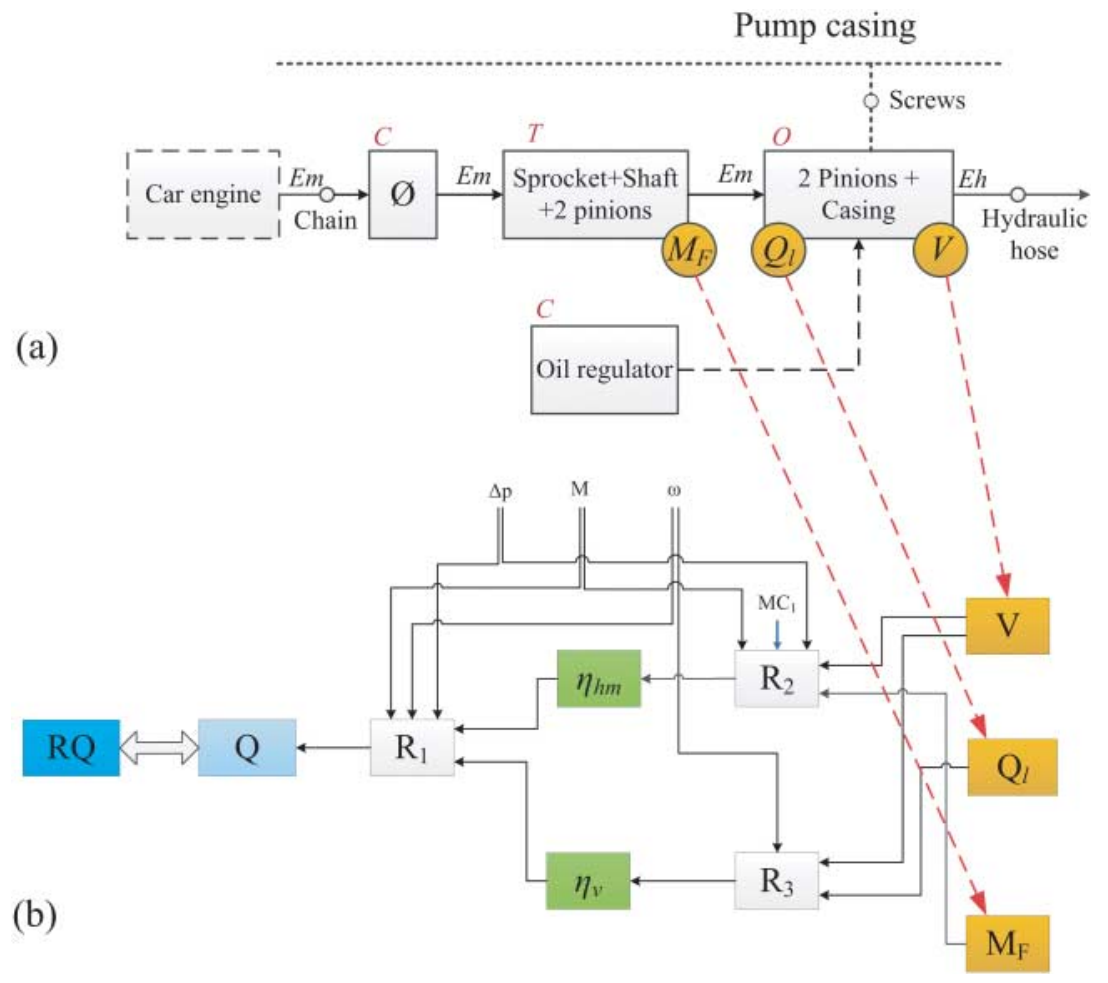

Figure 11. Second level of oil pump model: (a) structural model and (b) CPM.

Another parameter that has to be considered is temperature. This aspect is not presented in this paper. However, later in the calculation, the oil viscosity $(\mu)$ is taken into account as an effective parameter. The effect of temperature is simplified by keeping its value constant. Thus, regarding the parameters of $M, \omega, \Delta p$ and the efficiencies, $R_{1}$ is obtained as the first equation for $Q$

$$
Q=\frac{M \cdot \omega}{\Delta p} \times \eta_{v} \cdot \eta_{\mathrm{hm}}
$$

According to the functional model in Figure 9(a), the necessary decisions are made and the structural model is created. This model is illustrated in Figure 11(a). In an operator entity, the conversion of energy is by means of two gears and a casing. Transmitter consists of a sprocket, a shaft, and two small pinions. These entities must be correctly in interaction with each other in a proper surrounding (casing) to transfer the energy. The outlet flow is guided by means of a hose to the required areas to be lubricated. The hose is an interaction entity in CTOC. Moreover, to insure the pressure of the outlet oil an oil regulator is used as the entity of control. To be noted, in this figure two pinions are placed in both $O$ and $T$. The reason is that the volume of pinions transmits the mechanical energy $(T)$ while the transformation of mechanical energy into hydraulic energy happens by the teeth's surfaces and the casing $(O)$. 
The important parameter in transmitting mechanical energy $(T)$ is friction torque $\left(M_{\mathrm{F}}\right)$. The relation of this parameter with $\eta_{\mathrm{hm}}$ is as follows:

$$
\eta_{\mathrm{hm}}=\frac{V}{2 \pi \cdot\left(M-M_{\mathrm{F}}\right)} \Delta p
$$

The operator which is responsible for generating hydraulic energy into mechanical energy has two main parameters as oil displacement $(V)$ and flow loss $\left(Q_{1}\right)$. The relation of these parameters with the parameters in the previous level $\left(\eta_{\mathrm{v}}\right)$ should be found:

$$
\eta_{\mathrm{v}}=1-\frac{2 \pi \cdot Q_{1}}{V \cdot \omega}
$$

According to two equations of $\mathrm{R}_{2}$ and $\mathrm{R}_{3}$, the two IPs of $\eta_{\mathrm{V}}$ and $\eta_{\mathrm{hm}}$ are affected by the parameters of $V, M, \Delta p, \omega, Q_{1}$, and $M_{F}$. Since the parameters of $M, \Delta p$, and $\omega$ were considered as $\mathrm{EC}_{k}$ earlier, in the third level of CPM, $V, Q_{l}$, and $M_{\mathrm{F}}$ establish the next column of CPM as shown in Figure 11 (b).

In Figure 11, a modelling condition is indicated as $M C_{1}$. This condition is a simplification which is related to Equation $\left(\mathrm{R}_{2}\right)$. In the calculation of $\eta_{\mathrm{hm}}$ only the effect of friction torque is taken into account. Moreover, the friction torque effect is limited to the frictions in bearing and gear teeth. Similar simplifications and hypotheses are considered in other levels of the approach that all of them are shown as $M C_{n}$.

In this level, the entity of operator is studied in detail. This study is on two parameters of displacement $(V)$ and flow loss $\left(Q_{1}\right)$. To decompose the parameter of $V$, we assume that the tooth height is given by $2.25 \mathrm{~m}$ (this assumption is shown as $\mathrm{MC}_{2}$ ) the displacement $(V)$ by the pinions can be estimated as follows:

$$
V \approx 2.25 \times \pi \times \mathrm{m}^{2} \times Z \times L_{G} .
$$

The second parameter is the flow loss $\left(Q_{\mid}\right)$. Flow loss depends on backlashes between the components. These losses include external leakage and internal loss. The external leakage mostly happens because of the poor quality of the surfaces and assembly. Since this is not the current problem of the manufacturer, it is ignored in this design analysis $\left(\mathrm{MC}_{3}\right)$.

On the other side, the internal loss $\left(Q_{\mid}\right)$is unavoidable which is caused by the backlashes (gaps) required for moving parts. Nevertheless, it is possible to minimise it to increase the efficiency. Among the internal flow losses, two types are chosen: radial loss $\left(Q_{\mid r}\right)$ between the tips of the gear teeth and the case and axial loss $\left(Q_{\mathrm{la}}\right)$ through the gap between two mating surfaces by the side of the teeth. Axial loss is divided into two sections: the backlash on two sides of the teeth $\left(Q_{\text {lat }}\right)$ and the ring of the pinion that let the oil passes to the central shaft $\left(Q_{\text {lab }}\right)$. These flows are shown in Figure 12.

\subsection{Level 3: sub-systems' decomposition - obtaining characteristics}

This level is the level of detail in the proposed approach though it is still in the early stages of design. By using the energy flow in a hierarchical approach, we obtained a model that gives the designer enough information about the requirements of the system to satisfy the required function. So, based on this model, the designer can choose the structural options to have a complete model of the system. The result is shown in Figure 13 using the block diagram. We did not go into the detail in this model. 


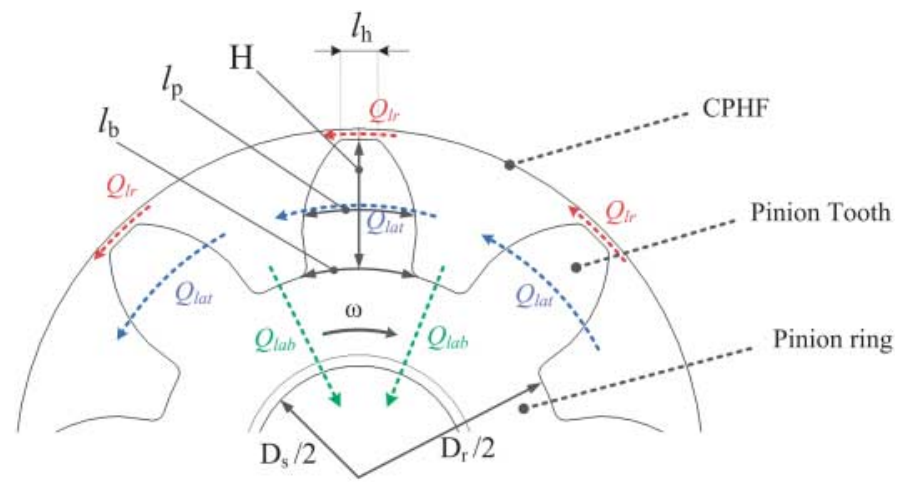

Figure 12. Radial and axial flow losses in a gear pump.

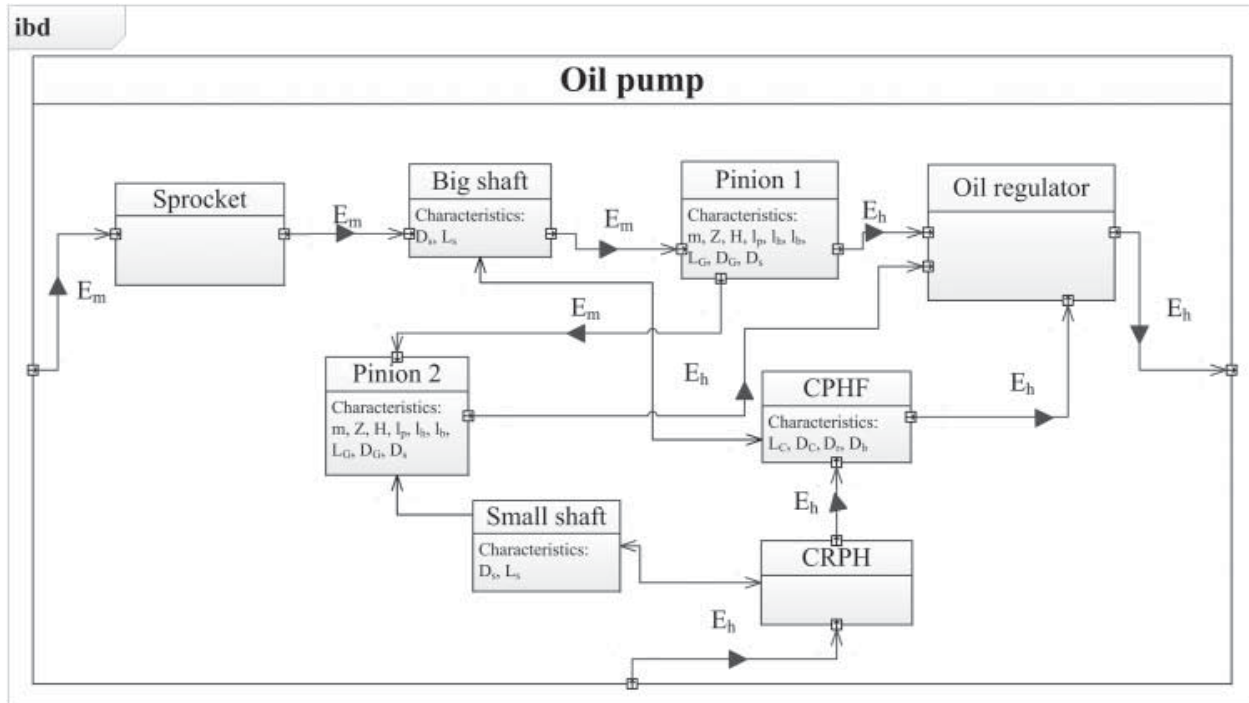

Figure 13. Level 3: structural model using block diagram.

Thus, the internal flow loss $\left(Q_{\mid}\right)$is:

$$
Q_{l}=Q_{\mathrm{lr}}+Q_{\text {lat }}+Q_{\mathrm{lab}}
$$

Two internal properties of $V$ and $Q_{\mid}$are decomposed by $R_{6}$ and $R_{4}$. The effective parameters of $V$ in $\mathrm{R}_{6}$ are geometrical dimensions. These parameters, based on the definition, are characteristics $\left(C_{i}\right)$. Though, $Q_{\mid}$is decomposed into three types of internal flow losses. These parameters are in the category of $\mathrm{IP}_{j}$ yet. So, the sub-system needs to be decomposed further and the effective parameters need to be determined.

To continue the synthesis phase in this level of decomposition, three effective parameters need to be decomposed. The radial flow loss is because of the backlashes between the teeth of the gear and the casing. In Figure 12, this backlash which is shown as $Q_{1 \mathrm{r}}$ is calculated as $\left(R_{7}\right)$. This formula is obtained from the Poiseuille equation. It is multiplied by two because of the existence of two gears in the pump. $(Z-3)$ denotes the number of teeth 

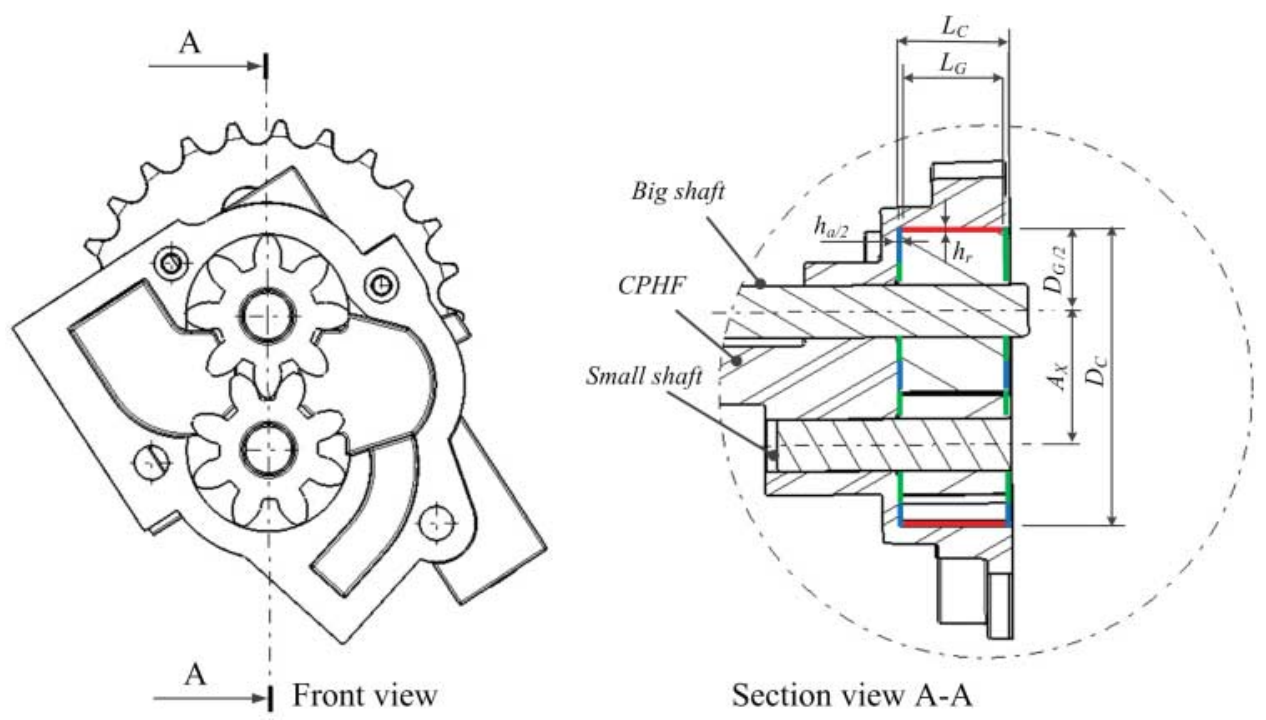

Figure 14. Backlashes in an external gear pump.

where radial flows exist

$$
Q_{\mathrm{lr}}=2 \times \frac{L_{G}{\overline{h_{\mathrm{r}}}}^{3}}{8 \mu \times(Z-3) \mathrm{l}_{\mathrm{h}}} \overline{\Delta p} .
$$

The axial backlash which causes the axial flow loss is on the two sides of the gears and the casing. This flow loss in the area that two gears are engaged acts differently which is shown in Figure 12. Considering the backlash on the two sides of each gear and using the Poiseuille equation, the flow loss is calculated as follows:

$$
Q_{\text {lat }}=\frac{H}{8 \mu \times \sqrt[3]{I_{\mathrm{h}} \cdot I_{\mathrm{p}} \cdot I_{\mathrm{b}}}}\left(\overline{h_{\mathrm{a}}} / 2\right)^{3} \cdot\left(\frac{2}{3}+\frac{4}{Z-3}\right) \overline{\Delta p} .
$$

In the formula, $\sqrt[3]{I_{\mathrm{h}} \cdot I_{\mathrm{p}} \cdot I_{\mathrm{b}}}$ is an estimation of the average tooth width. The third type of flow loss, due to the axial backlash between the gear and casing and to the direction of the shaft, is calculated as follows:

$$
Q_{\text {lab }}=4 \times \frac{2 \pi\left(\overline{h_{a}} / 2\right)^{3}}{8 \mu \cdot \ln \left(D_{r} / D_{s}\right)} \overline{\Delta p} .
$$

For better understanding of the obtained formulas, Figure 14 illustrates the backlashes accompanied by the related geometrical dimensions. The list of these parameters in addition to all other parameters in this case study is gathered in the table in the appendix.

It is important to remind that the objective of this study is not to model the exact flow of the oil pump as it is similarly done by Casoli, Vacca, and Berta (2008), Liping et al. (2011), Mucchi, Dalpiaz, and Fernàndez Del Rincòn (2015), Mucchi, Rivola, and Dalpiaz (2014), and Osiński, Deptuła, and Partyka (2013), but to have a close-to-reality functioning model to only show the proposed approach. So, the equations are simplified and other losses are ignored $\left(\mathrm{MC}_{4}\right)$. In addition, it is assumed that, gears are perfectly cantered in the casing $\left(\mathrm{MC}_{5}\right)$. But in 


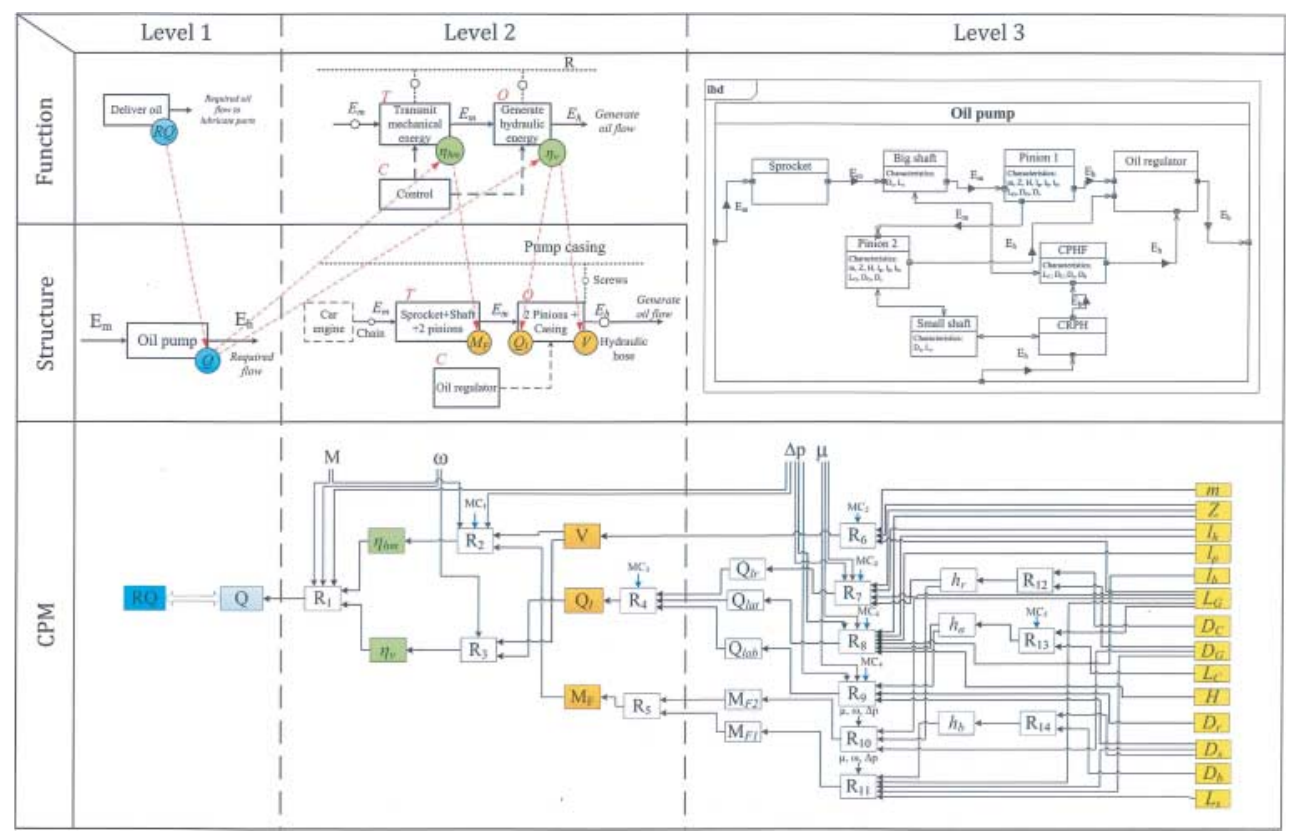

Figure 15. A global illustration of the proposed approach for modelling an oil pump.

reality, the axial backlash changes all the time during the rotation and calculation of the flow and pressure distributions are more complicated than the way presented here since they are pulsatory and transient (Casoli, Vacca, and Franzoni 2005; Vacca, Franzoni, and Casoli 2007).

In $R_{7}, R_{8}$, and $R_{9}$ all the parameters are $C_{i}$ except the backlashes $\left(h_{\mathrm{a}}\right.$ and $h_{\mathrm{r}}$ ). So, as before, the related formulas need to be determined. Every backlash is related to at least two geometrical dimensions:

$$
\begin{aligned}
& \overline{h_{\mathrm{r}}}=\frac{\operatorname{Min}\left(D_{\mathrm{C}}\right)-\operatorname{Max}\left(D_{\mathrm{G}}\right)}{2}, \\
& \overline{h_{\mathrm{a}}}=\min \left(L_{\mathrm{C}}\right)-\operatorname{Max}\left(L_{\mathrm{G}}\right) .
\end{aligned}
$$

Additionally, $M_{\mathrm{F}}$ should be decomposed. The detail of this decomposition $\left(R_{5}, R_{9}, R_{10}\right.$, $R_{11}$, and $R_{13}$ ) is not presented in this paper. However, related parameters are shown in the final model of the system.

Now, all the characteristics $\left(C_{i}\right)$ and external conditions $\left(E_{k}\right)$ are identified, the CPM representation of the model is complete. This model is shown in the CPM section of Figure 15. In this figure, all the $C_{i}$ are located in the rightmost column. So, with the first view of this model, one can see all the effective modifiable parameters of the system.

Thanks to the created model and identified the relations among the parameters, the following equation is obtained:

$$
\begin{aligned}
P_{j} & =f\left(C_{i}, E C_{k} \mid M C_{n}\right) \Rightarrow Q \\
& =f\left(m, Z, I_{\mathrm{h}}, l_{\mathrm{p}}, l_{\mathrm{b}}, L_{\mathrm{G}}, D_{\mathrm{C}}, D_{\mathrm{G}}, L_{C}, H, D_{\mathrm{r}}, D_{s}, D_{\mathrm{b}}, L_{s}, M, \omega, \Delta p, \mu \mid M C_{1}, M C_{2}, M C_{3}, M C_{4}, M C_{5}\right)
\end{aligned}
$$


Thanks to this equation, the effect of each $C_{i}$ or $\mathrm{EC}_{k}$ or the combination of them on $Q$ or any $\mathrm{IP}_{j}$ can be analysed using local sensitivity analysis (Saltelli et al. 2004). In addition, in a global sensitivity analysis (Saltelli et al. 2008), the importance of each parameter can be evaluated. This analysis can be used to optimise an existed product or to design a new product with high efficiency.

\section{Closure}

There are various models, approaches, and tools in each phase of design, but a quantitative approach to assure the transition from conceptual design phase to embodiment design phase is missing, though having links between the phases is essential. Such an approach should be able to create a link between functional requirements and physical structure of the designing system.

By aiming at this gap, this paper proposed an approach to help the designer in this transition, and model the physical structure of a system based on the minimum requirement to satisfy the required needs. As illustrated in Figure 5 and the case study in Figure 15, the approach includes three sections: functional domain, structural domain, and model section using CPM. By zigzagging between these two domains, the system is studied in a top-down approach and the model is determined as it is decomposed in each level.

In the proposed approach, CPM is used as the framework. Authors believe that CPM has a good potential for product modelling but it does not need to be limited to structural modelling. It can be used to create a quantitative functional model of a system and to insure the link between the two aforementioned design phases. However, as pointed out, there are drawbacks that led to the proposition of the approach in this paper including an extended version of CPM.

The extended version uses several levels of properties $\left(\mathrm{IP}_{j}\right)$ and by using the proposed approach, the model is determined in a systematic top-down approach. Thanks to the systematic decomposition tactic of the proposed approach, identifying the links between properties and characteristics is easier. Moreover, the result illustration is also more lucid in the analysis phase. So, compared to the proposition of Weber, it is more effective for complicated products. The proposed approach was presented step by step by using an industrial case study, so it can help to reduce ambiguity in the implementation of CPM.

One of the difficulties in CPM is to identify the design elements when the knowledge about the system's behaviour is limited. CTOC is used to model the physical structure based on the objective by insuring the transition from function to structure. So, it increases the designer's knowledge about the general structure of a system required to satisfy the required function. Therefore, it can also be used for managing complexity that is due to epistemic uncertainty as presented in Malmiry et al. ("Management of Product Design," 2016).

Since the physical structure is built based on the required function, the approach is applicable for modelling a new product as well as an existing product. The result of the approach can be used for sensitivity analysis to identify the impact of the variation in each $C_{i}$ or $\mathrm{EC}_{k}$ on the output $\left(P_{j}\right)$. For instance, in tolerancing, it can be used to evaluate the impact of the tolerance interval of each $C_{i}$ on the product performance (Malmiry et al., "From Functions to Tolerance," 2016). The sensitivity analysis can be deployed for product optimisation. 
One of the limitations of the approach is its applicability in modelling systems without energy flows. Though it is possible to use CTOC in this case as shown in (Pailhès et al. 2011), it is not very effective. The other limitation is the distinction of parameters of CPM which in some cases needs expertise and a minimum level of knowledge about the required subfunctioning of the studying system (mostly in $\mathrm{EC}_{k}$ and $\mathrm{MC}_{n}$ ).

Other than applying the proposed approach on an oil pump as presented in this paper, two systems of hair dryer (Malmiry et al., "Management of Product Design," 2016) and brake system for electric cars are modelled using the proposed approach to validate the generality and applicability of the approach. Modelling non-existing systems using the approach, uncertainty propagation by this approach and integrating cost analysis are some more perspectives for next steps after this study.

\section{References}

Altshuller, G. 1984. Creativity as an Exact Science. New York, NY: Gordon and Breach Science Publishers.

Altshuller, G. 1999. The Innovation Algorithm. Worcester, MA: Technical Innovation Center, Inc.

Altshuller, G. 2008. And Suddenly the Inventor Appeared - TRIZ, the Theory of Inventive Problem Solving. 8th ed. Worcester, MA: Technical Innovation Center, Inc.

Blessing, L. T. M., and A. Chakrabarti. 2009. DRM, a Design Research Methodology. London: Springer.

Borutzky, W. 2010. Bond Graph Methodology: Development and Analysis of Multidisciplinary Dynamic System Models. London: Springer.

Browning, T. R. 2001. "Applying the Design Structure Matrix to System Decomposition and Integration Problems: A Review and New Directions." IEEE Transactions on Engineering Management 48 (3): 292-306.

Casoli, P., A. Vacca, and G. L. Berta. 2008. “Optimization of Relevant Design Parameters of External Gear Pumps." Paper presented at the 7th JFPS international symposium on fluid power, Toyama.

Casoli, P., A. Vacca, and G. Franzoni. 2005. "A Numerical Model for the Simulation of External Gear Pumps." Paper presented at the 6th JFPS international symposium on fluid power, Tsukuba, 705-710.

Conrad, J., T. Deubel, C. Köhler, S. Wanke, and C. Weber. 2007. "Change Impact and Risk Analysis (CIRA) - Combining the CPM/PDD Theory and FMEA-Methodology for an Improved Engineering Change Management." Paper presented at the international conference on engineering design, ICED'07, August 28-31, 1-12.

Conrad, J., C. Köhler, S. Wanke, and C. Weber. 2008. "What Is Design Knowledge From the Viewpoint of CPM/PDD?" Paper presented at the international design conference - Design 2008, Dubrovnik, Croatia, 745-752.

Cross, N. 2000. Engineering Design Methods: Strategies for Product Design. 3rd ed. Chichester: Wiley.

Dantan, J.-Y., A. J. Qureshi, J. F. Antoine, B. Eisenbart, and L. T. M. Blessing. 2013. "Management of Product Characteristics Uncertainty Based on Formal Logic and Characteristics Properties Model." CIRP Annals - Manufacturing Technology 62 (1): 147-150.

Erbe, T., K. Paetzold, and C. Weber. 2011. "Actuation Principle Selection - An Example for TradeOff Assessment by CPM-Approach." Paper presented at the 18th international conference on engineering design (ICED 11), vol. 4, Copenhagen, Denmark, 222-229.

Friedenthal, S., A. Moore, and R. Steiner. 2012. A Practical Guide to SysML. 2nd ed. Waltham, MA: Elsevier.

Gero, J. S. 1990. "Design Prototypes: A Knowledge Representation Schema for Design." Al Magazine.

Gero, J. S., and U. Kannengiesser. 2004. "The Situated Function-Behaviour-Structure Framework." Design Studies 25 (4): 373-391.

Gero, J. S., and T. Mc Neill. 1998. "An Approach to the Analysis of Design Protocols." Design Studies 19 (1): 21-61. 
Grabowski, H., and R. Lossack. 2000. "The Axiomatic Approach in the Universal Design Theory." Paper presented at the proceedings of the first international conference on axiomatic design, Cambridge, $M A, 21-23$.

Grabowski, H., S. Rude, G. Grein, E. Meis, and E. El-Mejbir. 1998. “Universal Design Theory: Elements and Applicability to Computers." In Universal Design Theory, edited by H. Grabowski, S. Rude, and G. Grein, 209-220. Aachen: Shaker.

Gu, P., M. Hashemian, and A. Y. C. Nee. 2004. "Adaptable Design." Annals of CIRP 53 2: 539-557.

Henderson, M. R., and L. E. Taylor. 1993. "A Meta-Model for Mechanical Products Based upon the Mechanical Design Process." Research in Engineering Design 5 (3-4): 140-160. http://link. springer.com/article/10.1007/BF01608360.

Huang, G. 1996. Design for X: Concurrent Engineering Imperatives. Berlin: Springer.

Hubka, V., and W. E. Eder. 1987. "A Scientific Approach to Engineering Design." Design Studies 8 (3): 123-137.

Hubka, V., and W. E. Eder. 1996. Design Science. London: Springer.

Koening, H. E., Y. Tokad, and H. K. Kesavan. 1967. Analysis of Discrete Physical Systems. New York, NY: McGraw Hill.

Köhler, C., J. Conrad, S. Wanke, and C. Weber. 2008. "A Matrix Representation of the CPM/PDD Approach as a Means for Change Impact Analysis." Paper presented at international design conference - design 2008, Dubrovnik, Croatia, 167-174.

Le Masson, P., K. Dorst, and E. Subrahmanian. 2013. "Design Theory: History, State of the Art and Advancements." Research in Engineering Design 24 (2): 97-103. Accessed February 4, 2015. http://link.springer.com/10.1007/s00163-013-0154-4.

Liping, C., Z. Yan, Z. Fanli, Z. Jianjun, and T. Xianzhao. 2011. "Modeling and Simulation of Gear Pumps Based on Modelica/MWorks'," 421-429.

Lutters, E., F. J. A. M. Van Houten, A. Bernard, E. Mermoz, and S. L. Schutte. 2014. "Tools and Techniques for Product Design." CIRP Annals - Manufacturing Technology 63: 607-630.

Malmiry, R. B., J.-Y. Dantan, J. Pailhès, and J.-F. Antoine. 2016. "From Functions to Tolerance Analysis Models by Using Energy Flow Model in Characteristics-Properties Modelling." Procedia CIRP 43: 100-105. http://linkinghub.elsevier.com/retrieve/pii/S2212827116002274.

Malmiry, R. B., J. Pailhès, A. J. Qureshi, J.-F. Antoine, and J.-Y. Dantan. 2016. “Management of Product Design Complexity due to Epistemic Uncertainty via Energy Flow Modelling Based on CPM." CIRP Annals - Manufacturing Technology 65 (1): 169-172.

McDermott, R. E., R. J. Mikulak, and M. R. Beauregard. 1996. The Basics of FMEA. New York: Productivity Press.

Mizuno, S., and Y. Akao. 1993. QFD: The Customer-Driven Approach to Quality Planning \& Deployment. Tokyo: Asian Productivity Organization.

Mucchi, E., G. Dalpiaz, and A. Fernàndez Del Rincòn. 2015. “Elasto-Dynamic Analysis of a Gear PumpPart IV: Improvement in the Pressure Distribution Modelling." Mechanical Systems and Signal Processing 50-51: 193-213.

Mucchi, E., A. Rivola, and G. Dalpiaz. 2014. "Modelling Dynamic Behaviour and Noise Generation in Gear Pumps: Procedure and Validation." Applied Acoustics 77: 99-111.

Oppelt, W. 1972. Kleines Handbuch Technischer Regelvorgänge. 5th ed. Weinheim: Verlag Chemie.

Osiński, P., A. Deptuła, and M. A. Partyka. 2013. “Discrete Optimization of a Gear Pump after Tooth Root Undercutting by Means of Multi-Valued Logic Trees." Archives of Civil and Mechanical Engineering $13(4): 422-431$.

Pahl, G., W. Beitz, J. Feldhusen, and K.-H. Grote. 2007. Engineering Design: A Systematic Approach. 3rd ed. edited by K. Wallace and L. T. M. Blessing. London: Springer-Verlag.

Pailhès, J. 2013. "De L'analyse Fonctionelle et Physique À L'aide Decision En Conception." Univeristé Bordeaux 1.

Pailhès, J., M. Sallaou, and J. P. Nadeau. 2007. "Knowledge Base Formulation for Aided Design Tool." Advances in Integrated Design and Manufacturing in Mechanical Engineering II 231-243. doi:10.1007/978-1-4020-6761-7_16.

Pailhès, J., M. Sallaou, J.-P. Nadeau, and G. M. Fadel. 2011. "Energy Based Functional Decomposition in Preliminary Design." Journal of Mechanical Design 133 (May): 051011. 
Paynter, H. M. 1961. Analysis and Design of Engineering Systems. Cambridge: MIT Press.

Pektas, S. T., and M. Pultar. 2006. "Modelling Detailed Information Flows in Building Design with the Parameter-Based Design Structure Matrix." Design Studies 27: 99-122.

Qureshi, A. J., B. Eisenbart, J.-Y. Dantan, and L. T. M. Blessing. 2011. "Design Automation with the Characteristics Properties Model and the Property Driven Design for Redesign." Paper presented at the 23rd CIRP design conference, edited by M. Abramovici and R. Stark. Bochum: Springer Berlin Heidelberg, 563-572.

Saltelli, A., M. Ratto, T. Andres, F. Campolongo, J. Cariboni, D. Gatelli, M. Saisana, and S. Tarantola. 2008. Global Sensitivity Analysis - The Primer. Chichester: Wiley.

Saltelli, A., S. Tarantola, F. Campolongo, and M. Ratto. 2004. Sensitivity Analysis in Practice: A Guide to Assessing Scientific Models. Chichester: Wiley.

Savransky, S. D. 2000. Enginnering of Creativity (Introduction to TRIZ Methodology of Inventive Problem Solving). New York: CRC Press.

Suh, N. P. 1990. The Principles of Design. Oxford: Oxford University Press.

Suh, N. P. 2001. Axiomatic Design - Advances and Applications. New York: Oxford University Press.

Sushil, N. 1991. "Simplified Physical System Theory Model of a Closed Chain Production System." International Journal of Systems Science 22 (6): 987-999.

Sushil, N. 2002. “Physical System Theory: Fundamentals, Recent Developments and Relationships with System Dynamics." Kybernetes 31 (3/4): 496-528.

Sushil, N., S. N. Singh, and B. K. Jain. 1988. "A Physical System Theory Approach to Material Flow and Productivity Analysis." Engineering Costs and Production Economics 13 (3): 207-215.

Taguchi, G. 1987. The System of Experimental Design Engineering Methods to Optimize Quality and Minimize Cost, Vols. 1 and 2. Dearborn, Ml: American Supplier Institute.

Tichem, M. 1997. A Design Coordination Approach to Design for X. Delft: Delft University Press.

Tomiyama, T. 1997. "A Note on Research Directions of Design Studies." Paper presented at proceedings of the 11th ICED 1997, Tampere, Finland, 29-34.

Tomiyama, T., P. Gu, Y. Jin, D. Lutters, Ch. Kind, and F. Kimura. 2009. “Design Methodologies: Industrial and Educational Applications." CIRP Annals - Manufacturing Technology 58 (2): 543-565.

Vacca, A., G. Franzoni, and P. Casoli. 2007. "On the Analysis of Experimental Data for External Gear Machines." Paper presented at ASME international mechanical engineering congress and exposition, IMECE2007, Seattle, Washington, 1-9.

Weber, C. 2005a. "CPM/PDD - An Extended Theoretical Approach to Modelling Products and Product Development Processes." Paper presented at proceedings of the 2nd German-Israeli symposium on advances in methods and systems for development of products and processes, 159-179. Stuttgart: Fraunhofer-IRB.

Weber, C. 2005b. "Simulation Models of Machine Elements as Components of Mechatronic Systems." Paper presented at AEDS 2005 workshop, Pilsen, Czech Republic.

Weber, C. 2007. "Looking at 'DFX' and 'Product Maturity' from the Perspective of a New Approach to Modelling Product and Product Development Processes." Paper presented at the 17th CIRP design conference: The future of product development, 85-104. Berlin Heidelberg: Springer.

Weber, C. 2008. "How to Derive Application-Specific Design Methodologies." Paper presented at the 10th international design conference 2008, vol. 1,69-80, Dubrovnik, Croatia.

Weber, C. 2009. "Theory of Technical Systems (TTS) - Existing Approaches and Challenges." 17th international conference on engineering design, ICED'09, CA, 65-76.

Weber, C., H. Werner, and T. Deubel. 2003. "A Different View on Product Data Management/Product Life-Cycle Management and Its Future Potentials." Journal of Engineering Design 14 (4): 447-464. 
Appendix. List of the CPM elements in the case study.

\begin{tabular}{|c|c|c|c|}
\hline Parameter & & & Unit \\
\hline Characteristics $\left(C_{i}\right)$ & $\begin{array}{l}Z \\
m \\
I_{\mathrm{h}} \\
I_{\mathrm{p}} \\
I_{\mathrm{b}} \\
D_{\mathrm{C}} \\
D_{\mathrm{G}} \\
L_{\mathrm{C}} \\
L_{\mathrm{G}} \\
H \\
D_{\mathrm{r}} \\
D_{\mathrm{s}} \\
D_{\mathrm{b}} \\
L_{\mathrm{s}}\end{array}$ & $\begin{array}{l}\text { Number of teeth } \\
\text { Module of the gear tooth } \\
\text { Head length of the teeth } \\
\text { Primitive length of the teeth } \\
\text { Base length of the teeth } \\
\text { Interior casing distance } \\
\text { Gear diameter } \\
\text { Gear casing depth } \\
\text { Gear thickness } \\
\text { Tooth depth } \\
\text { Root diameter } \\
\text { Shaft diameter } \\
\text { Bearing diameter } \\
\text { Shaft length }\end{array}$ & $\begin{array}{l}\# \\
m \\
m \\
m \\
m \\
m \\
m \\
m \\
m \\
m \\
m \\
m \\
m \\
m\end{array}$ \\
\hline Intermediary properties $\left(\mathrm{IP}_{j}\right)$ & $\begin{array}{c}h_{\mathrm{r}} \\
h_{\mathrm{a}} \\
h_{\mathrm{b}} \\
Q_{\mathrm{lr}} \\
Q_{\mathrm{lat}} \\
Q_{\mathrm{lab}} \\
V \\
Q_{\mathrm{l}} \\
M_{\mathrm{F}} \\
M_{\mathrm{F} 1} \\
M_{\mathrm{F} 2} \\
\eta_{\mathrm{v}} \\
\eta_{\mathrm{hm}}\end{array}$ & $\begin{array}{l}\text { Radial backlash } \\
\text { Axial backlash } \\
\text { Bearing backlash } \\
\text { Radial leakage } \\
\text { Axial leakage (sides of teeth) } \\
\text { Axial leakage (sides of wheel) } \\
\text { Displacement } \\
\text { Internal leakage (flow loss) } \\
\text { Friction torque } \\
\text { Friction torque in bearing } \\
\text { Friction torque in gear teeth } \\
\text { Volumetric efficiency } \\
\text { Hydro-mechanical efficiency }\end{array}$ & $\begin{array}{c}\mathrm{m} \\
\mathrm{m} \\
\mathrm{m} \\
\mathrm{m}^{3} / \mathrm{s} \\
\mathrm{m}^{3} / \mathrm{s} \\
\mathrm{m}^{3} / \mathrm{s} \\
\mathrm{m}^{3} / \mathrm{rev} \\
\mathrm{m}^{3} / \mathrm{s} \\
\mathrm{Nm} \\
\mathrm{Nm} \\
\mathrm{Nm} \\
\% \\
\%\end{array}$ \\
\hline$P_{j}$ & $Q$ & Flow & $\mathrm{m}^{3} / \mathrm{s}$ \\
\hline $\mathrm{EC}_{k}$ & $\begin{array}{l}\Delta p \\
M \\
\Omega \\
\mu\end{array}$ & $\begin{array}{l}\text { Pressure rise } \\
\text { Input torque } \\
\text { Angular rotational velocity } \\
\text { Dynamic viscosity of the fluid }\end{array}$ & $\begin{array}{l}\mathrm{Pa} \\
\mathrm{Nm} \\
\mathrm{rad} / \mathrm{s} \\
\mathrm{Pas}\end{array}$ \\
\hline
\end{tabular}

